RASĀYAN J. Chem.

Vol. 13 | No. 3 |2020-2026| July - September | 2020 ISSN: 0974-1496 | e-ISSN: 0976-0083 | CODEN: RJCABP

\title{
FAST AND ADVANCED ANALYTICAL METHOD FOR DETERMINATION OF PERMETHRIN (CIS AND TRANS) CONTENT AND IN TRACES BY ULTRA PERFORMANCE LIQUID CHROMATOGRAPHY
}

\author{
K. Sumanth Prabhu, ${ }^{1, *}$ A. Venkatachalam ${ }^{2}$ and Subhash Kale ${ }^{3}$ \\ ${ }^{1}$ Research Scholar, Faculty of Pharmacy, Pacific Academy of Higher Education and Research \\ University, Udaipur-313024 (Rajasthan) India. \\ ${ }^{2}$ Research guide, Faculty of Pharmacy, Pacific Academy of Higher Education and Research \\ University, Udaipur-313024 (Rajasthan) India. \\ ${ }^{3}$ Research Scholar, Faculty of Science, Pacific Academy of Higher Education and Research \\ University, Udaipur-313024 (Rajasthan) India \\ *E-mail: ksumanthprabhu@gmail.com
}

\begin{abstract}
Pyrethroids are ester of dichloro analog compound that called as Permethrin. Permethrin is widely used as pesticide and insecticide, and off-late as an ectoparasiticide. It is majorly used for effective and short term treatment against lice that is usually found in human and animal head and body hair. Further, Permethrin can also be used against infections namely scabies that formed from insects namely Mite in humans and also in human immunodeficiency virus-infected patients. Isomers of Permethrin differ in their toxicity while (1R, 3S)-trans as well as (1R, 3R)cis isomers are typically effective for the insects killing properties.

Permethrin is usually available in cream or lotion form of formulation in the market hence; it is applied on the skin as a cream or lotion. Further estimation of Permethrin in an environment samples like Waste/Potable water and pharmaceuticals is important as a control strategy during environment (water pollution) monitoring, formulation batch release and stability study.

This research study emphasizes on the development of an Ultra Performance Liquid Chromatography (UPLC) based rapid detection and quantitation with an accurate and precise analytical method for Permethrin and its traces by an Ultra Performance Liquid Chromatography. The external standard method is used for assay determination in Waste/Potable water, and Cream formulation samples. To prove the suitability of the developed analytical method for its intended purpose, its validation study was performed following an International council for Harmonization guidelines.
\end{abstract}

Keywords: Permethrin, Scabies, Lice, Mite, UPLC, External standard, Method validation, Waste/Potable water, Cream formulation.

CRASĀYAN. All rights reserved

\section{INTRODUCTION}

Pyrethroids have been in use for a few decades. ${ }^{1}$ Permethrin is formulated as cream/lotion for skin applications, sprayed on mosquito nets or clothing as a repellent to kill the insects that touch them. As an ectoparasiticide used against the killing of lice found in the hair on the head and body of human and animals $^{2}$ (Fig.-1). It is further effective against Mite infected disease like scabies (Fig.-2 and 3) and also in humans with HIV (human immunodeficiency virus) infected patients. ${ }^{3}$ Permethrin paralyzes and kills the Mites and Lice directly as well as destroy their eggs. It has a wide range of applications being used also as a pesticide, insecticide because it has highly potent action against Lice and Mite type of insects.

Due to carcinogenic classification by USEPA (the United States Environment Protection Agency) and differential toxicity of its isomer, its control to human exposure has become important from a safety and toxicity perspective. Hence it is essential to develop and apply the analytical method for identification and

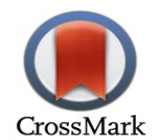


RASĀYAN J. Chem.

Vol. 13 | No. 3 |2020-2026| July - September | 2020

individual quantitation in environment samples like waste/potable water to study water pollution as well as in pharmaceuticals during batch release and stability study.

Permethrin chemical compound has a total of four types of stereo isomers ${ }^{5}$ (two pairs of enantiomeric forms); those are arising from the two types of stereocenters in the cyclo-propane ring. The Transform of enantiomeric pair is called as trans-permethrin. In fact (1R, 3S)-trans and (1R, 3R)-cis types of enantiomers are responsible for the insecticidal properties of Permethrin ${ }^{4}$. Permethrin is insoluble in water and it is photostable.

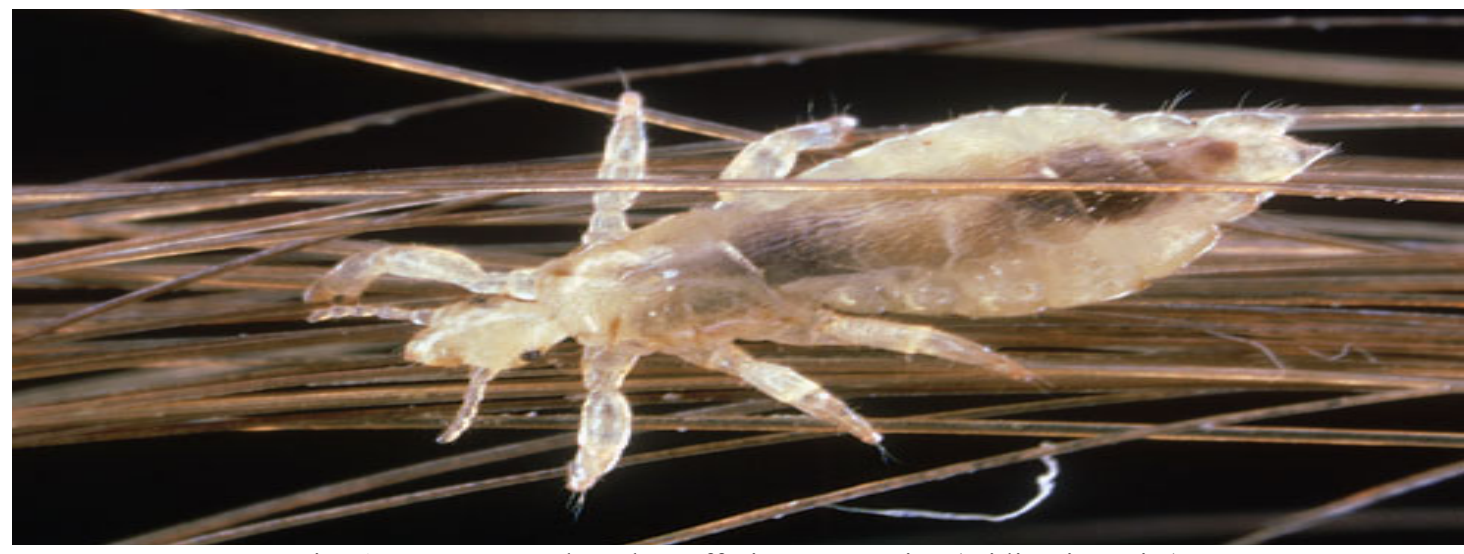

Fig.-1: Human Head Scalp Suffering From Lice (Hiding in Hairs)

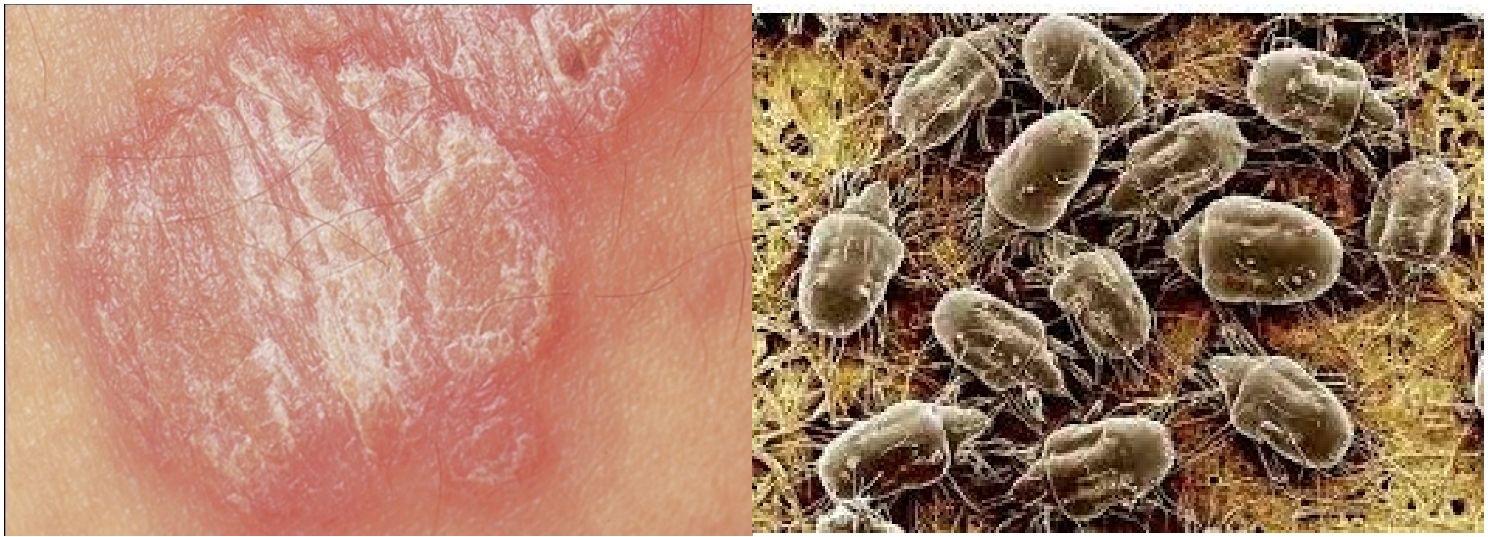

Fig.-2: Human Skin Suffering From Scabies

Fig.-3: Human Skin Suffering Srom Mites that Causes Scabies

\section{Permethrin Stereochemistry}

The four stereo-isomers ${ }^{5}$ are depicted in Fig.-4 to Fig.-8.<smiles>CC1(C)[C@@H](C=C(Cl)Cl)[C@H]1C(=O)OCc1cccc(Oc2ccccc2)c1</smiles>

Fig.-4: Permethrin (Cis and Trans)<smiles>CC1(C)C(C(=O)OCc2cccc(Oc3ccccc3)c2)[C@@H]1C=C(Cl)Cl</smiles>

Fig.-6: (1R,3S)-trans Enantiomer<smiles>CC1(C)C(C(=O)OCc2cccc(Oc3ccccc3)c2)[C@@H]1C=C(Cl)Cl</smiles>

Fig.-5: (1S,3R)-trans Enantiomer<smiles>CC1(C)C(C(=O)OCc2cccc(Oc3ccccc3)c2)[C@@H]1C=C(Cl)Cl</smiles>

Fig.-7: (1S,3S)-cis Enantiomer 
RASĀYAN J. Chem.

Vol. 13 | No. 3 |2020-2026| July - September | 2020

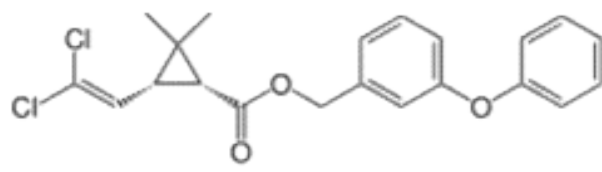

Fig.-8: (1R,3R)-cis Enantiomer

The main purpose of present research study on Permethrin chemical drug was to develop rapid, accurate and precise chromatography (UPLC) based analytical technique for determination of Permethrin which has total four stereoisomeric (two enantiomeric pair) forms in waste/potable water as a part of environmental pollution monitoring and its traces by Ultra Performance Liquid Chromatography. ${ }^{6,7}$ Further UPLC was considered superior over the conventional HPLC ${ }^{8,9}$ (High-performance liquid chromatography) methods which either have very long run time (up to $80 \mathrm{~min}$ and higher) as against UPLC that have less than 15 min total run time and or being specific to one kind of formulation (not universal) etc. The effort and challenges were in developing the chromatography which can determine Permethrin even in trace amounts in waste and potable water sample in addition to the pharmaceuticals. The external standard method is used here for the assay determination in waste/potable water, and creambased formulation.

\section{Materials and Methods}

\section{EXPERIMENTAL}

Permethrin Standard, Purified water, Ammonium acetate (GR grade), Ortho-phosphoric acid (GR grade), Methanol (Chromatography grade, filtered through $0.22 \mu \mathrm{m}$ filter), Permethrin cream $5 \% \mathrm{w} / \mathrm{w}$ formulation product (procured commercially from local pharmacy store) and its placebo (prepared inhouse).

\section{Samples for Analysis \\ Formulation}

Permethrin (Cis and Trans) - 5\% w/w in a cream base.

\section{Potable and Wastewater}

(*Details captured under "Potable and Wastewater samples collection procedure")

\section{Instruments Required}

pH meter, UPLC from Waters Corporation USA (Model - ACQUITY UPLC H-Class PLUS System), Weighing balance, Vortex stirrer, Analytical glassware's and Sonicator.

\section{General Procedure}

Standard Solution-1

$0.2 \mathrm{mg} / \mathrm{mL}$ of Permethrin in diluent (dissolved by sonication).

\section{Standard Solution-2}

$0.05 \mathrm{mg} / \mathrm{mL}$ of Permethrin in diluent (dissolved by sonication).

\section{Sample Solution-1 (for Formulation Cream)}

Weigh accurately about $1.0 \mathrm{~g}$ of cream sample (equivalent to $50 \mathrm{mg}$ of Permethrin) in $50 \mathrm{~mL}$ of the volumetric flask, add $20 \mathrm{~mL}$ diluent, sonicate to dissolve and dilute to volume with the diluent. Sonicate for $5 \mathrm{~min}$ and mix. Further pipette $5 \mathrm{~mL}$ of this solution into $25 \mathrm{~mL}$ volumetric flask and dilute with the diluent and mix.

\section{Sample Solution-2 (for Waste and Potable Water)}

Transfer $100 \mathrm{~mL}$ of duly filtered (through $0.45 \mu \mathrm{m}$ Nylon filter) sample into $250 \mathrm{~mL}$ evaporating dish. Carefully evaporate liquid part of the sample till dryness and dissolve an obtained residue with $10 \mathrm{~mL}$ of methanol and mix. 
RASĀYAN J. Chem.

Vol. 13 | No. 3 |2020-2026| July - September | 2020

\section{Placebo Solution}

Weigh accurately about $1.0 \mathrm{~g}$ of placebo (without Permethrin) in $50 \mathrm{~mL}$ volumetric flask, dissolve the content in $20 \mathrm{~mL}$ of diluent through sonication and dilute to volume with the diluent. Sonicate for $5 \mathrm{~min}$ and mix. Further, transfer $5 \mathrm{~mL}$ of this solution to $25 \mathrm{~mL}$ volumetric flask and dilute with the diluent and mix.

\section{Potable and wastewater sample collection procedure ${ }^{10,11}$}

Scabies and Lice related diseases are very common in the slum area where people live in unhygienic conditions. Due to this issue, physicians often prescribe Permethrin lotion/cream/shampoo type of medication to treat lice and scabies in a slum area to get rid of related infections. After the application of lotion/cream/shampoo, the residual Permethrin in drug formulation gets washed away during bathing or cleaning of the infected body part. This untreated Permethrin remains in wastewater which then mixes with potable water through contamination due to unhygienic sanitation practices. Thus from potable water, Permethrin gets ingested into the human body that causes health hazards related to this drug. Hence, it was decided to collect wastewater and potable water samples from the Dharavi slum area which is the largest slum in Mumbai (India) and Asia region. Total 6 samples of wastewater and potable water each were collected from different locations (Table-1).

Table-1: Details of Wastewater / Potable Water Samples From Different Locations of Dharavi Slum Area

\begin{tabular}{c|c|c}
\hline Sample ID & Sampling Location & Co-ordinates \\
\hline${ }^{\$}$ DWW-1\& DPW-1 $^{\prime}$ & Bhatiya nagar & DMS Decimal 19॰2 24.75" N, \\
$72^{\circ} 51^{\prime} 3.06^{\prime \prime} \mathrm{E}$ \\
DWW-2 \& DPW-2 & Tadwadi lane & $19.040208,72.85085$ \\
DWW-3 \& DPW-3 & Dharavi Crossroad & Geo URI \\
\hline DWW-4 \& DPW-4 & Sheshwadi road & $19.040208,72.85085$ \\
\hline DWW-5 \& DPW-5 & Machi galli & \\
\hline DWW-6 \& DPW-6 & Kala Killa road &
\end{tabular}

${ }^{\$} \mathrm{DWW}$ - Dharavi wastewater \& ${ }^{*} \mathrm{DPW}$ - Dharavi potable water

\section{Detection Method}

Chromatographic Conditions

Instrument

Column

Column Temperature

Mobile Phase

Elution Mode

Diluent: Methanol

Pump Flow Rate

Detector

Injection Volume

Auto-sampler Temperature

Total Gradient Run Time
: UPLC (Ultra High-Performance Liquid Chromatography), Make Waters Corp. USA.

: Ethylene Bridged Hybrid ODS, (2.1 mm ID x 50 mm Length), 1.7 micrometers,

$: 25^{\circ} \mathrm{C}$

: A - 0.05M Ammonium acetate buffer, B - Methanol

: Gradient elution

: Water [90:10]

: $0.4 \mathrm{~mL} / \mathrm{min}$,

: UV (235 nanometer),

: 1.0 microliter

$: 25^{\circ} \mathrm{C}$,

: $13 \mathrm{~min}$

Preparation of Blank, Placebo, Standard and Sample solutions:

Blank Solution : Used diluent as blank

Table-2: UPLC Gradient Elution Program

\begin{tabular}{c|c|c|c|c}
\hline S. No. & Time (min) & Pump Flow Rate $(\mathrm{mL} / \mathrm{min})$ & A-Port (\%) & B-Port (\%) \\
\hline I & Initial & 0.40 & 60 & 40 \\
\hline II & 4 & 0.40 & 60 & 40 \\
\hline III & 5 & 0.40 & 20 & 80 \\
\hline IV & 9 & 0.40 & 20 & 80 \\
\hline V & 10 & 0.40 & 60 & 40 \\
\hline VI & 13 & 0.40 & 60 & 40 \\
\hline
\end{tabular}


RASĀYAN J. Chem.

Vol. 13 | No. 3 |2020-2026| July - September | 2020

\section{Analytical Discussion}

\section{Method Development and Optimization (Formulation Samples and Waste/Potable Water Sample)}

A UPLC chromatographic condition was established after several preliminary experiments on UPLC for selecting the proper reverse phase $\mathrm{C} 18$ stationary phase, mobile phase $\mathrm{pH}$ and gradient proportion. Different gradient programs were tested, and selection of the suitable gradient program (Table-2) that estimates Permethrin content precisely and accurately in less run time $(13 \mathrm{~min})$ depended on its ability to pass system suitability parameters as mentioned in Table-3. Satisfactory system suitability criteria achieved on BEH C-18 (Ethylene Bridged Hybrid ODS), $(2.1 \mathrm{~mm}$ x $50 \mathrm{~mm}), 1.7 \mu \mathrm{m}$ using gradient program as mentioned in Table-3. Mobile phase with varying gradient proportion of Ammonium acetate buffer $(0.05 \mathrm{M})$ and Methanol used to achieve satisfactory resolution between Cis and Tran Permethrin. Overall runtime set to be 13 min with completion of gradient and stabilization for next run.

Table-3: System Suitability of Test Method

\begin{tabular}{c|c|c|c|c}
\hline \multirow{2}{*}{ Parameter } & Acceptance Criteria & Cream & Wastewater & $\begin{array}{c}\text { Potable } \\
\text { Water }\end{array}$ \\
\cline { 2 - 5 } & & \multicolumn{3}{|c}{ Permethrin } \\
\hline Tailing factor & NMT 2.0 & 1.06 & 1.21 & 1.32 \\
\hline Theoretical plates & NLT 2000 & 8050 & 4562 & 3980 \\
\hline $\begin{array}{c}\text { RSD (\%) of six injections } \\
\text { (Standard response) }\end{array}$ & $\begin{array}{c}\text { NMT 3 \% For cream and NMT } \\
10 \% \text { for waste/ potable water } \\
\text { assay }\end{array}$ & $0.29 \%$ & $4.96 \%$ & $6.24 \%$ \\
\hline $\begin{array}{c}\text { RSD (\%) of six injections } \\
\text { (Standard RT) }\end{array}$ & NMT 1 \% & $0.62 \%$ & $0.88 \%$ & $0.93 \%$ \\
\hline
\end{tabular}

Intra-day precision and Inter-day precision (Ruggedness) have been established for the proposed method with \%-RSD (Relative standard deviation) for intraday found to be $0.68 \%$ and that for inter-day $1.65 \%$ for Assay test of cream while \%-RSD for intraday found to be $5.25 \%$ and that for inter-day $6.05 \%$ for assay of wastewater samples and \%-RSD for intraday found to be $7.62 \%$ and that for inter-day $8.11 \%$ for assay of potable water samples indicating preciseness of proposed UPLC method for Permethrin determination in the Cream formulation, wastewater and potable water samples.

\section{Accuracy}

Accuracy of the developed UPLC method was established at three different levels i.e. $50 \%, 100 \%$ and $150 \%$ of test (Permethrin) concentration by adding a known amount of Permethrin standard into the placebo and in highly purified water. Further, each level prepared in triplicate and estimating the sample on the UPLC test method. Three sets in triplicate were prepared and analyzed separately for the Cream formulation, wastewater and potable water samples.

\section{Robustness}

Robustness was established by deliberately changing instrument parameters of test methods like flow rate, buffer $\mathrm{pH}$ and wavelength of UV detector were carried out as per ICH guidelines to estimate their effects on the proposed method.

\section{RESULTS AND DISCUSSION}

System suitability parameters namely theoretical plates per meter (TPPM), tailing factor (peak asymmetry), and percentage relative standard deviation of area response and Permethrin peak retention time of six injections were carried out and the values are well within the United States Pharmacopoeia (USP) limits as shown in Table-3 indicating UPLC system was technically working properly as per desired output for assay determination of Permethrin in the Cream formulation, water and potable water samples.

From the linearity results where a linear calibration plot of Permethrin was constructed at seven point concentration levels. From the values of $r^{2}$ obtained as above, it could be proved that, the proposed method for Permethrin Assay in the Cream formulation and waste/potable water samples is linear for the specified working range. The typical linearity plot is given as Fig.-9. 
RASĀYAN J. Chem.

Vol. 13 | No. 3 |2020-2026| July - September | 2020

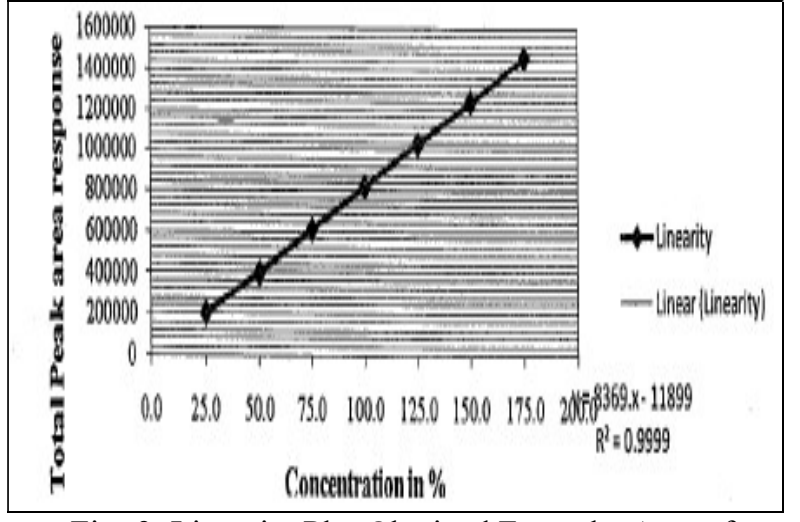

Fig.-9: Linearity Plot Obtained From the Area of Standard Permethrin

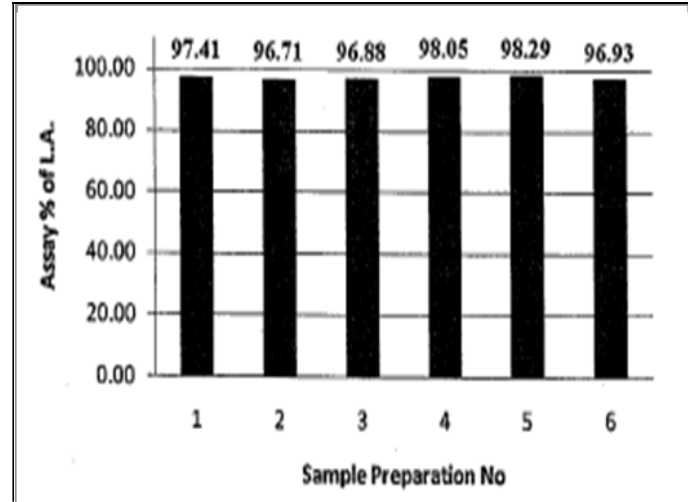

Fig.-10: Precision Plot Obtained From 6 Assay Values of Permethrin Content in the Cream Formulation

The precision (termed as method reproducibility) of an assay method was evaluated for repeatability or reproducibility and for intermediate precision which is also called method ruggedness of the method. For the precision experiment, the percentage relative standard deviation for the assay of Permethrin for 6 Assay determinations was found to be within the specified limits for Cream formulation and waste/potable water samples. Thus method precision characteristic to the method is proved. Obtained results are given in Table-4 with graphical representation in Fig.-10.

Table-4: Precision and Intermediate precision \& Linearity $\left(\mathrm{n}^{\wedge}=7\right)\left[\mathrm{n}^{\wedge}\right.$ - No of injections]

\begin{tabular}{|c|c|c|c|c|c|}
\hline \multirow{2}{*}{\multicolumn{2}{|c|}{ Parameter }} & \multirow{2}{*}{ Limits } & Cream Product & Wastewater & Potable Water \\
\hline & & & \multicolumn{3}{|c|}{ Permethrin } \\
\hline \multirow{2}{*}{$\begin{array}{c}\text { Precision }(\% \\
\text { RSD })\end{array}$} & Repeatability & $2.0 \%$ & 0.68 & 5.25 & 7.62 \\
\hline & Intermediate & $2.0 \%$ & 1.65 & 6.05 & 8.11 \\
\hline Linearity $\left(r^{2}\right)$ & 7 - Levels & $\begin{array}{c}0.998 \text { For cream } \\
\text { and } 0.995 \text { for w/p } \\
\text { water assay }\end{array}$ & 0.9999 & 0.9967 & 0.9958 \\
\hline
\end{tabular}

A known amount of Permethrin standards were spiked at $50 \%, 100 \%$, and $150 \%$ concentration levels in placebo as well as in purified water and each level performed in triplicate. From the results obtained, percentage recoveries (\%-Accuracy) of drugs were calculated for Permethrin content. The \%-recovery at three different concentrations found to be within the range of $97.0 \%$ to $103.0 \%$ limit set by ICH guidelines for the Cream formulation and within $80.0 \%$ and $120.0 \%$ for waste/potable water samples indicating proposed UPLC based method is accurate. The \%-recovery or accuracy results are summarized in Table-5.

Table-5: Accuracy (\%-Recovery)

\begin{tabular}{c|c|c|c}
\hline \multirow{2}{*}{ Accuracy Levels } & Cream Formulation & Wastewater & Potable Water \\
\cline { 2 - 4 } & $\begin{array}{c}\text { \%-Mean Recovery } \\
\text { ( (Limit: 97.0\%-103.0\%) }\end{array}$ & $\begin{array}{c}\text { \%-Mean Recovery } \\
\text { (Limit: 80.0\%-110.0\%) }\end{array}$ & $\begin{array}{c}\text { \%-Mean Recovery } \\
\text { (Limit: 80.0\%-110.0\%) }\end{array}$ \\
\hline Level-1 (50\%) & 98.07 & 88.07 & 86.87 \\
\hline Level-2 (100\%) & 97.45 & 92.80 & 94.71 \\
\hline Level-3 (150\%) & 100.45 & 105.22 & 107.42 \\
\hline
\end{tabular}

The robustness of the assay method was studied by incorporating small but deliberate changes in critical analytical method parameters (i.e. variation in flow rate, buffer $\mathrm{pH}$ and UV (Ultraviolet) detector wavelength). In all the varied UPLC instrument conditions; there was no significant change in system suitability parameters indicating a proposed method for Permethrin estimation in the Cream formulation and waste/potable water samples is Robust.

\section{CONCLUSION}

Finally, based on the summarized data as above, it could be concluded that we have precisely and accurately developed a proposed method for Permethrin estimation in potable/wastewater and formulation 
RASĀYAN J. Chem.

Vol. 13 | No. 3 |2020-2026| July - September | 2020

samples. The developed method is duly validated following ICH guidance document. The developed method is new (i.e. our innovation), simple, rapid, precise and accurate, external standard based UPLC method for the estimation of Permethrin in Cream (OTC-Over the counter) Formulation, wastewater and potable water samples. This developed method has proved that instruments like UPLC can be extremely useful in the estimation of Permethrin compound in the cream formulation and at trace levels in waste/potable water samples in less time (i.e. within $13 \mathrm{~min}$ ) due to its high pressure and characteristic small particle size stationary phase. Hence developed method proved to be very cost-effective as well as time-saving with user friendly.

The proposed method is duly validated and shall be applied for routine estimation of Permethrin in creambased or similar other formulations with a minor change in sample preparation. This formulation is mainly used against the killing of Mites that causes Scabies and Lice that are usually observed in the hair scalp of the head in humans and animals.

Thus, this method can be applied for the estimation of Permethrin content in Cream as well as similar other several formulations available in the market that contain Permethrin as an active ingredient in OTC products. For other formulations, some modifications in sample preparation as well as UPLC conditions may be required based on types of inactive ingredients present in such formulations.

Further, this method helped during the estimation of Permethrin content in waste and potable water samples indicating potable water in the slum area is getting contaminated with Permethrin from wastewater. Further study is needed in this regard.

\section{ACKNOWLEDGMENT}

The authors were thankful to "RELIABLE's SHREE INDUSTRIAL TRAINING CENTER", First Floor, Lathi Plaza, Opp. Shahu Maharaj Complex, Jalgaon (Maharashtra - India) for allowing to use analytical and instrumental facilities to carry out experimental work mentioned in this research paper. While Permethrin cream drug product OTC samples were taken from Indian Pharmaceutical Market.

\section{REFERANCES}

1. Maja A. Shishovska, Marina T. Stefova, Journal of Chromatographic Science, 50(1),43(2012), DOI: 10.1093/chromsci/bmr014

2. C.V. Bainbridge, G.L. Klein, S.I. Neibart, Clinical Paediatrics, 37,17(1998), DOI: 10.1177/000992289803700103

3. W. Liu, J.J. Gan, S. Qin, Chirality,17, S127(2005), DOI:10.1002/chir.20122

4. Julia Dornetshuber, Wolfgang Bicker, Michael Lämmerhofer, Wolfgang Lindner, Anneliese Karwan, Wilfried Bursch, BMC Pharmacology, 7 (Supplement2), A65, DOI:10.1186/1471-2210-7S2-A65.

5. R. Manadas, F. Veiga, J. J. Sousa, M.E. Pina, Journal of Liquid Chromatography, 22, 1867(1999) DOI: $10.1081 / J L C-100101772$

6. E. Garca, A. Garca, C. Barbas, Journal of Pharmaceutical and Biomedical Analysis, 24(5), 999(2001), DOI: 10.1016/s0731-7085(00)00544-6

7. Jing Ye, Meiging Jin, Weiping Liu, American Chemical Society, Symposium Series, 1085, (2011), DOI: $10.1021 / \mathrm{bk}-2011-1085 . c h 005$

8. A. Novas Dias, F. Garcia Sanchez, A. Garcia Paveja, Journal of Chromatography Science, 36(4), 211(1998), DOI: 10.1093/chromsci/36.4.210

9. M. Shishovska, V. Trajkovska, Chirality, 22(5), 527(2010), DOI:10.1002/chir.20773

10. Nivruti T. Nirgude, Sanjay Shukla and A. Venkatachalam, Rasayan Journal of Chemistry, 6(1), 47 (2013).

11. Nivruti T. Nirgude, Sanjay Shukla and A. Venkatachalam, Rasayan Journal of Chemistry, 6(1), 68(2013).

12. ICH, Guidance on Analytical Method Validation, International Convention on Quality for the Pharmaceutical Industry, Toronto, Canada: International Conference on Harmonization(2002).

13. ICH, Harmonized Tripartite Guidelines, Validation of Analytical Procedures: Text and Methodology Q2 (R1), International Conference on Harmonization(2005).

[RJC-5820/2020] 